\title{
Design optimisation of an offshore vertical axis wind turbine
}

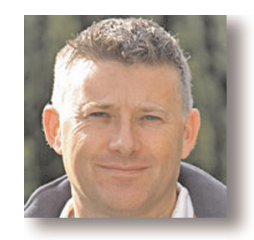

Andrew Shires EngD

Senior Lecturer, Offshore, Process and Energy Engineering Department,

School of Engineering, Cranfield University, Cranfield, UK

Horizontal axis wind turbines have a number of limitations for offshore operations, particularly in deep water (i.e. over $50 \mathrm{~m}$ ). For example, scalability restrictions, the necessity for high lift installations offshore requiring specialist vessels, high gravitational and aerodynamic moments on the support structure and a need to maintain rotary equipment at heights typically over $60-80 \mathrm{~m}$. Conversely, vertical axis wind turbines have several inherent attributes that offer some advantages for offshore operations, particularly their scalability and low over-turning moments with better accessibility to drivetrain components. This paper describes the aerodynamic optimisation of a novel $10 \mathrm{MW}$ vertical axis wind turbine rotor shape offering a low-stress design to minimise manufacturing and maintenance costs of the whole turbine assembly including the supporting structure and foundations. The Aerogenerator vertical axis wind turbine is self-supporting so does not require a supporting tower, giving a low centre of gravity and producing significantly lower aerodynamic over-turning moments than conventional vertical axis wind turbines or horizontal axis wind turbines, making it a credible option for a floating, deep water platform. A numerical optimisation procedure is described to minimise the Aerogenerator weight while imposing aerodynamic, mechanical and structural side constraints. The study proposes a novel 'sycamore'-shaped rotor design that demonstrates a lower cost of energy compared with conventional offshore turbines.

\section{Motivation}

The evolution of wind turbines has largely been driven by the cost of energy. During the 1980s this led to the demise of many vertical axis wind turbine (VAWT) concepts giving lower cost effectiveness compared with horizontal axis wind turbines (HAWTs), owing to the following factors (Tangler, 2000).

- VAWT blades generally use symmetrical aerofoils with a lower lift-to-drag ratio than cambered aerofoils tailored to maximise HAWT rotor performance. Furthermore, the use of active blade pitch control to maximise performance for different operating conditions is mechanically simpler for HAWTs.

- Rotor wake-induced losses of VAWTs are greater than those of HAWTs.

- VAWTs generally operate at lower altitudes, reducing the energy that can be captured due to wind shear.

- Structurally, the highly cyclic power and thrust generated by VAWT rotors results in higher fatigue loads.

- Mechanically, a VAWT tends to operate at lower $\mathrm{r} / \mathrm{min}$, which can result in greater machine weight and cost.

Recently, however, there has been a resurgence of interest in the development of VAWTs (Dodd, 2011; Kaminski, 2011; Marsh and Peace, 2005; Sutherland et al., 2012; Vita et al., 2009; www.floatingwindfarms.com; www.vertaxwind.com), particularly for offshore wind energy generation. This can largely be attributed to the increasing costs of offshore HAWT installations, particularly for deeper water sites. In 2000 the average capital expenditure for installations of offshore wind was approximately $£ 1.2$ million per megawatt (BWEA, 2009). Since 2009, this cost has been approximately $£ 3.1$ million per megawatt (Low Carbon Innovation Coordination Group, 2012) and operating costs increased by approximately $65 \%$ over the same period. These costs are highly dependent on the site characteristics, specifically water depth, distance to shore and the local wind resources. In the offshore environment for example, installation and cabling costs can account for $40-50 \%$ of project costs (Marsh, 2005) so economies of scale, utilising fewer larger turbines, can be significant. A recent UK government report (Low Carbon Innovation Coordination Group, 2012) acknowledges that the marinisation of conventional onshore machines is not necessarily the best option offshore, particularly for deep water sites. An optimum offshore machine must take account of life-cycle costs for the whole system including the foundations, supporting structures, drivetrain, rotor, electrical connections and offshore installation and maintenance operations. 
Although there is currently significant research effort to improve the aerodynamic efficiency of VAWT rotors, their aerodynamic efficiency is unlikely to challenge that of HAWT rotors. While VAWTs are capable of achieving a peak power coefficient of 0.4 (Morgan et al., 1989), HAWT rotors can achieve power coefficients approaching $0 \cdot 5$. However, VAWTs have a number of other attributes that offer some advantages for offshore operations with the potential to reduce the overall cost of energy relative to offshore HAWTs.

The lower operating height of VAWTs is less of a disadvantage offshore where winds are stronger and more consistent at low altitudes (due to a lower surface roughness reducing wind shear). Indeed, the lower supporting tower of a VAWT with the drivetrain located near the base of the turbine is a significant advantage for offshore operations, simplifying installation and maintenance owing to its accessibility and minimising the need for high lift operations offshore. Although failure rates within the wind industry are low relative to other industries the costs of failure, replacing the gearbox from a nacelle $80 \mathrm{~m}$ above sea level for example, can be very high (Tavner et al., 2007). A lower centre of gravity and lower over-turning moments (OTMs) due to aerodynamic loads also reduce costs for the supporting structure and improve the hydrodynamic stability of a potential deep water floating platform. The more simple design of a VAWT can also be an advantage for offshore operations; no blade pitch control or yaw mechanism to maintain and a relatively simple blade shape that reduces manufacturing costs for large structures.

Both HAWTs and VAWTs are subject to the same laws of scaling. However, HAWT edgewise blade loads due to gravity tend to increase significantly more with increasing blade radius than aerodynamic loads. Indeed, some commentators are questioning how much bigger HAWT rotor blades can get (Marsh, 2005), owing to the self-weight induced fatigue loading of their blades. The blades of VAWTs are not affected by gravity in the same manner. As rotor size increases, therefore, the cyclic gravitational loading of HAWT blades creates a greater fatigue loading on the blades and supporting structure than the cyclic aerodynamic loading of VAWT blades.

Therefore, although VAWT designs are unlikely to influence onshore and shallow water offshore installations in significant numbers, they offer a real opportunity to reduce costs for deep water installations where economies of scale are necessary owing to high installation, cabling and maintenance costs.

\section{VAWT developments: a brief history}

While early examples of VAWTs were developed by the Persians over 1000 years ago, the modern VAWT was developed in the years following the first oil crisis of 1973. These later designs are based on an idea patented in 1922 by the
French engineer, Georges Darrieus, with straight or curved 'lifting' blades rotating about a vertical tower.

During the 1970s and 1980s significant research and development effort in both the USA and Canada led to several curvebladed (or $\Phi$-rotor) Darrieus test turbines. These prototypes proved to be quite efficient and reliable (Eriksson et al., 2008). The largest VAWT, built in 1986, was the $96 \mathrm{~m}$ tall Éole Darrieus wind turbine pictured in Figure 1, located at Cap-Chat, Québec, Canada. With a rated maximum power of $3.8 \mathrm{MW}$, it produced $12 \mathrm{GWh}$ of electric energy during the 5 years it operated but was shut down in 1993 owing to a failure of the bottom bearing.

Attempts to commercialise these VAWT developments were made in the USA during the 1980s by FloWind Ltd. Several wind farms were constructed, based on the Sandia National Laboratories $17 \mathrm{~m}$ dia. test machine. Although these machines worked efficiently, they experienced fatigue problems with the blades (Eriksson et al., 2008).

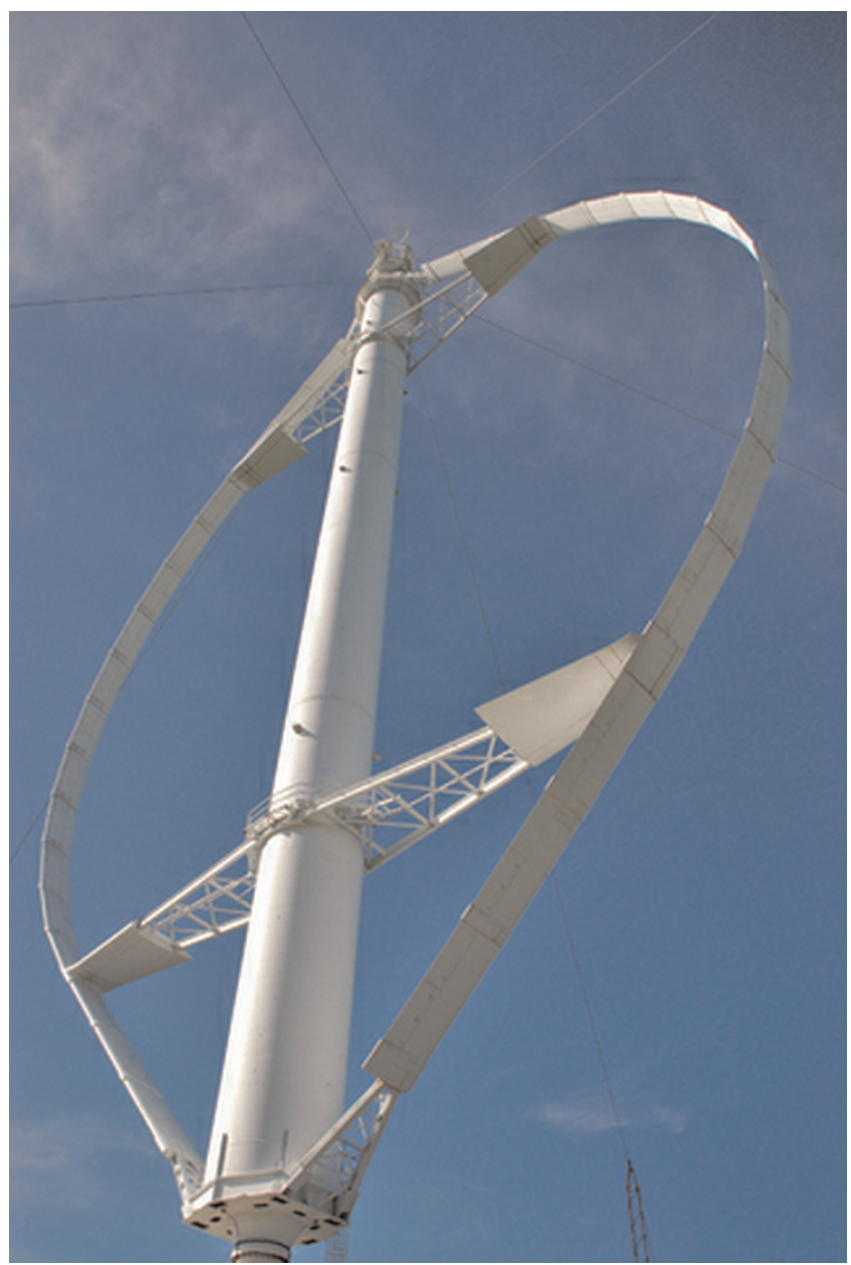

Figure 1. 3.8 MW Éole VAWT $\Phi$-rotor 
The straight-bladed Darrieus turbine or H-rotor was largely developed in the UK by Peter Musgrove during the 1980s and 1990s. The H-rotor aimed to reduce blade manufacturing costs and simplify the support structure, relative to the $\Phi$-rotor, with a shorter tower and by avoiding the need for guy support wires. Several test machines were constructed in the UK by VAWT Ltd (Clare and Mays, 1989), the largest being the $0.5 \mathrm{MW}$ VAWT-850 machine pictured in Figure 2 built in 1990 (Mays et al., 1990). However, the VAWT-850 suffered a blade failure after a few months of operation due to a manufacturing fault that curtailed any further VAWT developments (Price, 2006).

The V-rotor, first proposed by Olle Ljungstrom in 1973 (Ljungstrom, 1986), aimed to mimic the lower half of a $\Phi$-rotor. It had the advantage of a shorter tower than a $\Phi$ or H-rotor and avoided the horizontal (and therefore dragging) struts and supporting arms of $\Phi$ and H-rotors.

A $5 \mathrm{~kW}$ two-bladed V-rotor prototype was designed and successfully tested in 1987 by David Sharpe and Derek Taylor (Sharpe et al., 1987). Following testing of the twin-bladed machine, they also proposed a mono V-VAWT pictured in Figure 3, consisting of one inclined blade (with associated balance weights) mounted on a teetered hub above a relatively short support structure. The single cantilevered blade was predicted to improve performance with a lower cost of manufacture.

Despite these VAWT developments, problems with fatigue failures due to the high dynamic loads and a poor wind energy market in the USA contributed to a reduction in financial support for VAWT development projects in the 1990s. The last of the Sandia VAWTs was dismantled in 1997 after cracks were found in its foundations (Eriksson et al., 2008). However, the quest for larger offshore turbines that can deliver

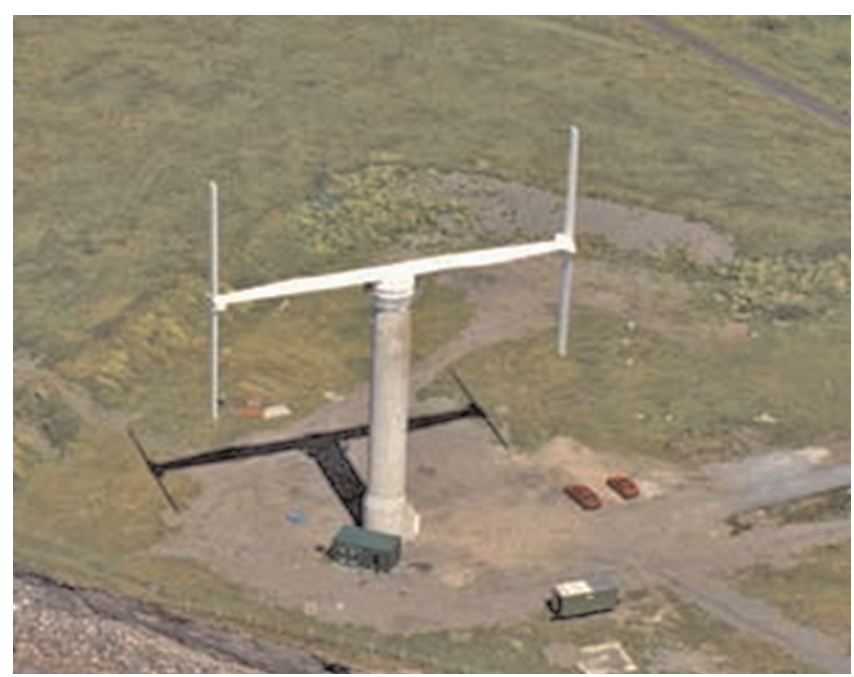

Figure 2. 0.5 MW VAWT-850 H-rotor

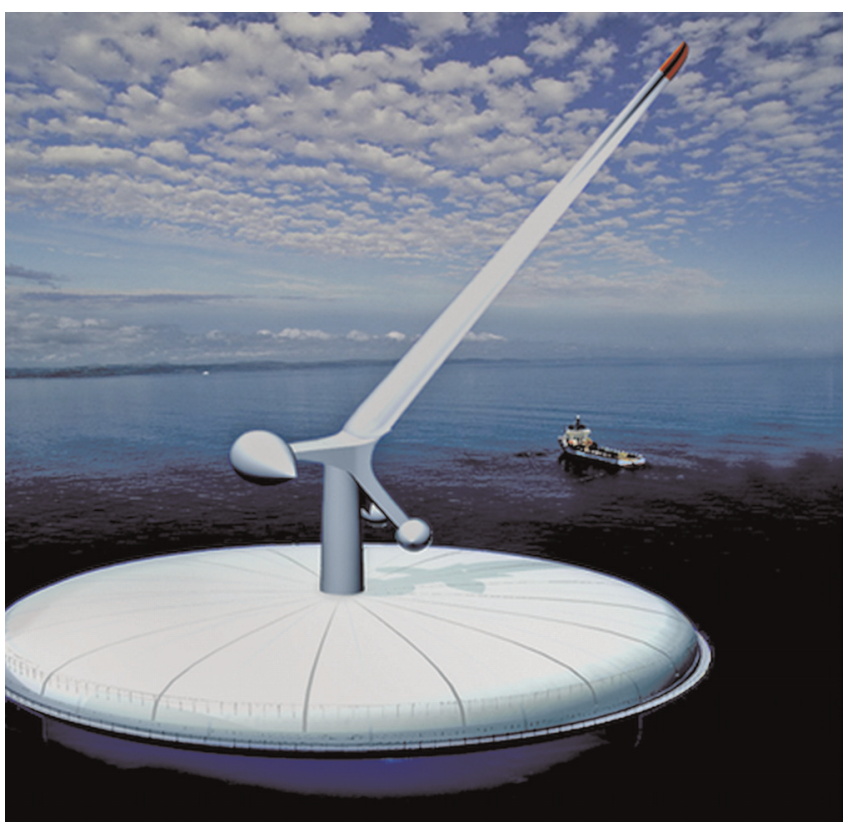

Figure 3. Mono V-VAWT concept (courtesy of Wind Power Ltd, 2004)

economies of scale and a need for deep water solutions have led to a recent resurgence of interest in VAWTs. In a recent review of VAWT technologies and economics Sandia concluded that VAWTs 'have significant advantages over HAWTs in off-shore applications' (Sutherland et al., 2012) and that $\mathrm{H}$ or V-rotor designs are likely to be more cost effective.

Recent development of VAWT machines includes in 2009 a $35 \mathrm{~kW}$ prototype of the VertiWind concept in France. This Hrotor has helical blades to reduce the torque and OTM ripple and is supported on a tilting base capable of simulating the operation of a floating VAWT (Snieckus, 2012). Work is due to start in 2012 on a $2 \mathrm{MW}$ floating prototype. However, although the helical rotor concept should improve the cyclic loading, the support structure will still experience relatively high stresses compared with the V-rotor concept. In 2010 Vertical Wind installed a grid-connected $200 \mathrm{~kW}$ three-bladed H-rotor near Falkenberg, Sweden, with no gearbox and a direct driven generator at the base of the tower (http://www. verticalwind.se). Owing to the high-torque, low-r/min operation of a VAWT, it is likely that a novel drivetrain will be required particularly for large offshore machines. Other recent research interest largely focuses on the dynamics of floating VAWTs (Akimoto et al., 2011; Vita et al., 2009) and improving blade section aerodynamic performance including blade pitching concepts or giromills (Kirke and Lazauskas, 2008). However, most research and development activity is focused on $\mathrm{H}$ or curved-bladed $\Phi$-rotor concepts and research to advance the V-rotor concept is limited. 


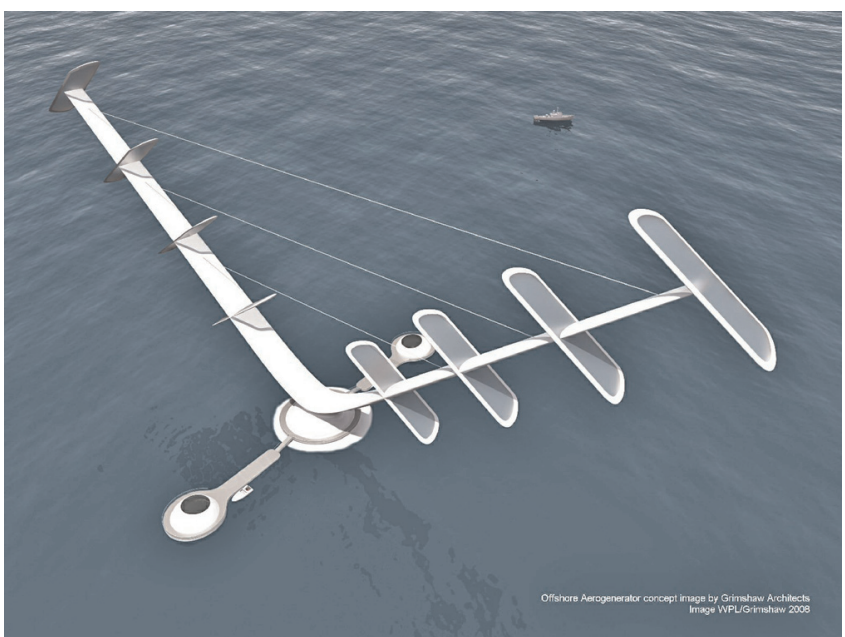

Figure 4. Original NOVA V-VAWT concept (courtesy of Wind Power Ltd and Grimshaw, 2005)

\section{The Aerogenerator concept}

The original Aerogenerator concept was proposed by David Sharpe and developed by Wind Power Ltd with structural engineers Atelier one. It combined a V-rotor with several blades or sails positioned along the span that are angled to minimise the aerodynamic OTMs, as depicted in the artist's impression in Figure 4. This design concept and principle is protected by a Wind Power Ltd patent (see UK patent application 05803712.8).

The NOVA project matured the concept through design optimisation and detailed technological, economic and environmental assessment compared with a baseline conventional offshore HAWT turbine. The NOVA conceptual design study was commissioned by the Energy Technologies Institute, which invested $£ 2.8$ million to develop the concept, and Wind Power Ltd. A consortium that included industrial partners Wind Power Ltd, OTM Consulting, QinetiQ, James Ingram Associates, CEFAS and DNV-GEC, as well as Cranfield, Strathclyde and Sheffield Universities, developed the novel $10 \mathrm{MW}$ offshore Aerogenerator wind turbine concept over a period of 18 months.

The fundamental design focus was to demonstrate the scalability of the rotor concept and to explore the potential cost of electricity reductions that can be achieved for a $5 \mathrm{GW}$ wind farm, by reducing the weight and height of components while increasing energy yield with ultra-high availability.

\section{Configuration optimisation}

This paper specifically describes design optimisation studies to explore the aerodynamic design freedoms and constraints of the concept. These designs were not necessarily aimed at maximising aerodynamic efficiency but delivering a low-stress design to minimise manufacturing and maintenance costs of the whole turbine assembly including the supporting structure and foundations. Therefore, in parallel with these designs other studies included the structural design of the composite blades and of the steel hub and support structure, the structural dynamics, the mechanical design of the drivetrain and the control system (NOVA Consortium, 2010). These parallel studies utilised aerodynamic loads data derived from the aerodynamic designs described in this paper. Two support structures were considered; a fixed jacket structure for a $40 \mathrm{~m}$ water depth and a floating semi-sub structure for a $60 \mathrm{~m}$ water depth (Collu et al., 2010). Analysis of both structures included foundation or mooring analysis and loads due to ocean waves, aerodynamics and the rotor inertia. Although loads over the entire operating envelope were considered, the critical loads case was generally the extreme $70 \mathrm{~m} / \mathrm{s}$ storm wind condition. It was assumed that the blades could not be feathered, nor could the rotor be positioned in a favourable orientation to the wind direction. Stationary extreme storm loads were estimated using datasheet methods and used to size the blade, support structure and drivetrain. Consequently to minimise the drivetrain dimensions, structural ratings and therefore cost, a structural bypass was proposed that connects the rotor directly to the supporting structure, bypassing the drive shaft and bearings during survival mode (NOVA Consortium, 2010). Fatigue analysis of the composite blades and jacket support structure also demonstrated that the turbine could be expected to operate safely over the whole 20-year lifetime (NOVA Consortium, 2010). This analysis used conservative assumptions of peak stresses from the cyclic hydrodynamic and aerodynamic loads, although it did not include unsteady aerodynamic loads due to freestream turbulence. Dynamics analysis also ensured that periodic frequencies do not coincide with the natural frequencies of the rotor (NOVA Consortium, 2010) and as some of the natural modes could be excited at certain rotor speeds the control system had to exclude these conditions.

A large number of designs were performed and this paper presents some of the key results from those designs. Design constraints were continuously modified to incorporate new or modified limits imposed by structural, mechanical and control considerations. Also, as the blade aerofoil geometry (i.e. the camber and thickness distribution) does not significantly influence VAWT rotor performance, unlike a HAWT rotor blade, a symmetrical NACA $00^{* *}$ series aerofoil is assumed. Therefore, designs were focused on optimising the configuration shape (i.e. the spans, chords, orientations and positions of the blades and their supporting arms and struts) to minimise stresses and weights. The designs had to achieve a rated electrical power of $10 \mathrm{MW}$ at $13 \mathrm{~m} / \mathrm{s}$ wind speed (measured at $80 \mathrm{~m}$ above sea level), assuming a drivetrain efficiency of $88 \%$.

\subsection{Aerodynamic performance model}

A reliable validated methodology for predicting aerodynamic performance is clearly essential for assessing potential turbine 
Energy

Volume 166 Issue EN1
Design optimisation of an offshore

vertical axis wind turbine

Shires rotor designs. However, predicting the aerodynamic loads of VAWT rotors is non-trivial with blades operating with both attached and separated flow regimes and blade elements passing through multiple wakes, giving a range of complex flow physics. A new aerodynamic performance model was developed for the NOVA project with the flexibility to model $\Phi, \mathrm{H}$ and V-rotor VAWT configurations so that it could be evaluated against existing measured data and thereby give confidence in the accuracy of the method. The aerodynamic performance model is based on Paraschivoiu's double-multiple streamtube model (Paraschivoiu, 1988). As it relies on blade element momentum theory, the standard approach for the wind industry, it is a relatively fast method to use and ideal for incorporation in an optimisation routine. The method includes Gormont's dynamic stall model (Gormont, 1973) with corrections (Berg, 1983; Masse, 1981), as well as allowances for wind shear and tower losses. Loads are evaluated for all of the rotor components including blades, supporting arms and struts, which also contribute to the induced velocity field. Three-dimensional considerations are included by assuming a Prandtl lift loss and an induced drag increment for all components with unbounded tips. Furthermore, the drag associated with the secondary vortices that form in junction regions is included based on the empirical junction drag proposed by Roach and Turner (1985).

As with other blade element momentum models, the NOVA model uses a database of static aerofoil lift and drag coefficients that are interpolated for the relevant Reynolds number and angle of attack (AoA). The NOVA turbine model also allows the inclusion of a family of aerofoils so that the effect of shape variables, such as maximum thickness, can be represented in the design process. Measured characteristics from wind tunnel tests of the NACA00** series of aerofoils, ranging in thickness from $12 \%$ chord to $25 \%$ chord (Sheldahl, 1981), were used exclusively in the design of the configuration. Poststall characteristics were represented by an analytical expression for a flat plate lift and drag.

The turbine model showed good agreement of predicted power with measured data for a $230 \mathrm{~kW}$ and $500 \mathrm{~kW}$ Ф-rotor VAWT as well as a $105 \mathrm{~kW}$ and $500 \mathrm{~kW}$ H-rotor VAWT over a wide range of operating conditions. Figure 5 compares the power predicted using the turbine model with measured data for the 105 kW VAWT-260 H-rotor (Morgan et al., 1989). Good agreement is achieved over the full range of wind speeds, including the post-stall region above a wind speed of approximately $10 \mathrm{~m} / \mathrm{s}$. In addition, the turbine model was evaluated for the NOVA concept using measured data from testing of a $5 \mathrm{~kW}$ prototype device pictured in Figure 6 performed by Wind Power Ltd. Although there was some scatter in the measured data, the predicted power was in reasonable agreement.

\subsection{Design method}

The numerical optimisation procedure developed for the project is illustrated in Figure 7. This procedure optimises several parameters that describe the shape of the rotor configuration, while minimising or maximising an objective function (e.g. torque) and constraining other functions controlling aspects of the structure (e.g. minimum blade thickness) or aerodynamic characteristics (e.g. peak OTM). Aerodynamic performance information is derived through analysis using the NOVA turbine model.

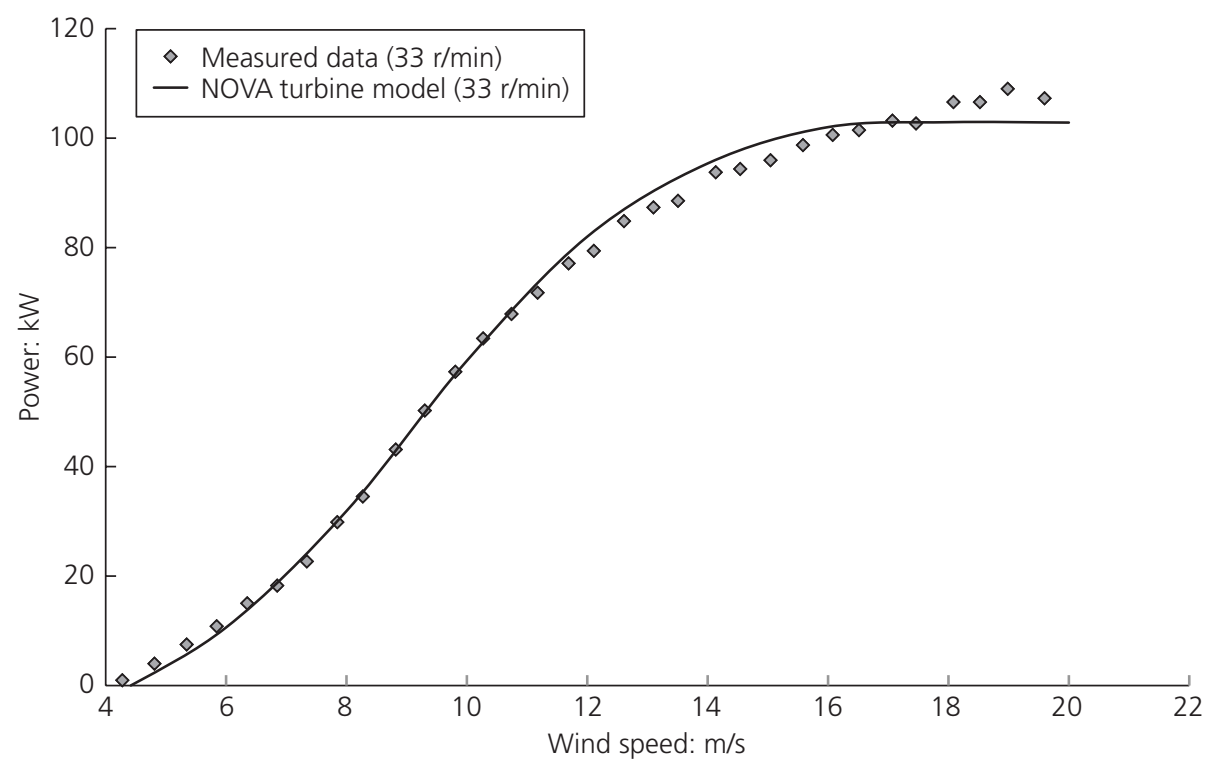

Figure 5. Predicted power of the VAWT-260 H-rotor 


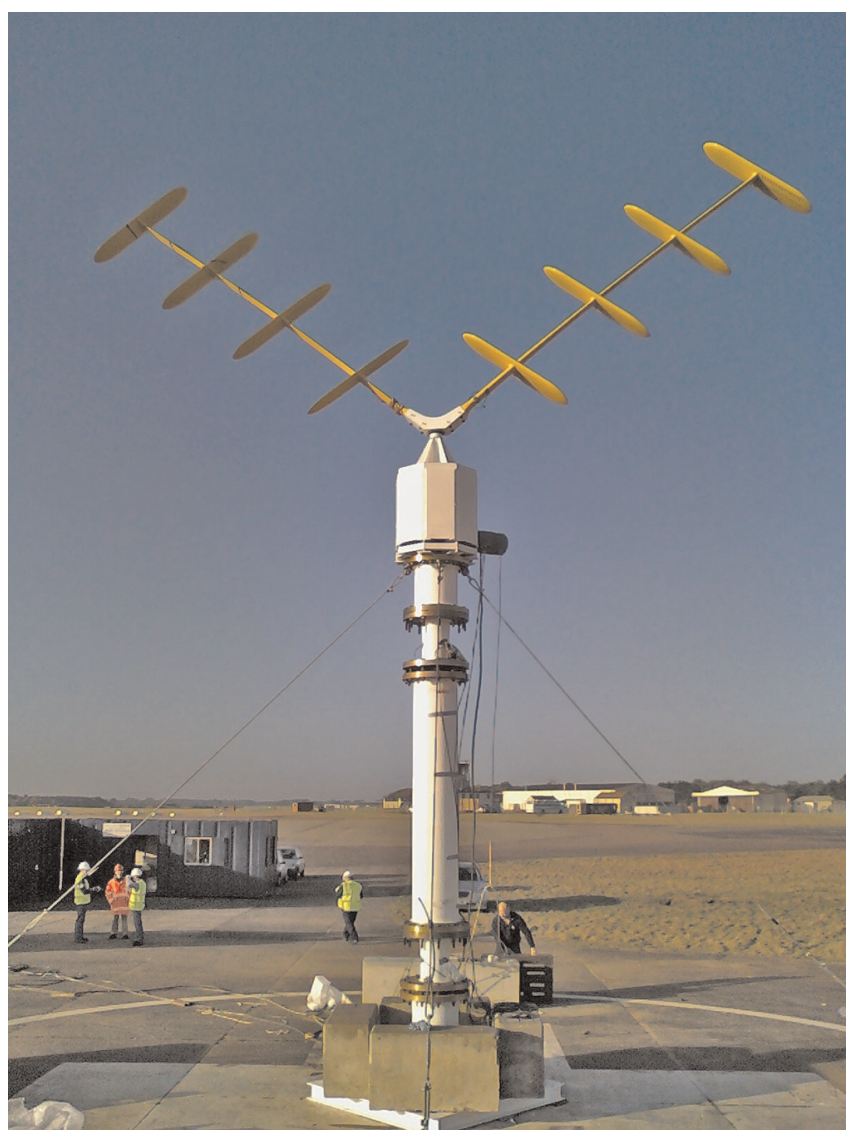

Figure 6. $5 \mathrm{~kW}$ prototype of the NOVA V-VAWT

A non-linear, gradient-search type, constrained optimisation routine, RQPMIN (Doherty and Lovell, 1994) is used in the optimisation procedure, developed by QinetiQ. The gradientsearch technique is a recursive two-stage process in which gradient evaluation is followed by a series of search steps. At the gradient evaluation stage each design variable is perturbed separately and the effect on the objective and constraint functions is calculated. A complete set of variable perturbations enables the gradient of the objective and constraint functions, with respect to each of the design variables, to be defined.

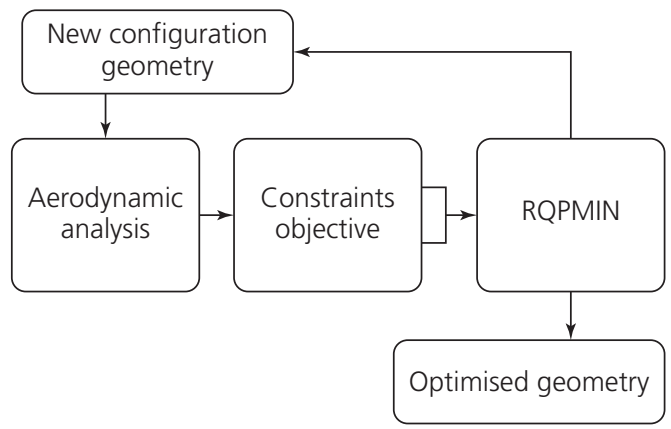

Figure 7. Schematic diagram of the design procedure
This gradient information defines a strategy for varying the complete set of variables to reduce the value of an objective function, while satisfying the constraint functions. The RQPMIN optimisation routine was originally developed in the 1980s, but has since been used for a wide range of advanced design applications including motorsport (Shires and Alderman, 2004) and Airbus cruise wing shape (Alderman and Shires, 2006).

Developing a procedure for the optimisation of the NOVA rotor configuration required the construction of a rotor geometry from approximately 25 design variables defined by the RQPMIN routine, and subsequent aerodynamic analysis of the rotor geometry using the turbine model at a number of operating conditions. From the mean and peak aerodynamic loads derived for this geometry, the objective and constraint functions are updated and provided to the RQPMIN routine. Owing to the non-linear nature of the objective and constraint functions, several gradient-search steps, or design cycles, are generally required to obtain an optimised solution that satisfies the objective and constraint functions within predefined tolerances.

\subsection{Design objectives}

Unlike the operation of a HAWT rotor a VAWT rotor blade sees an inconsistent AoA through its rotation. The reciprocating action requires VAWT blades to backtrack against the wind for part of the cycle, which leads to a cyclic variation in torque and lateral wind loading over the course of a rotation.

Taking the case of a mid-span blade element of a small H-rotor VAWT operating at $35 \mathrm{r} / \mathrm{min}$ with a wind speed of $14 \mathrm{~m} / \mathrm{s}$, the predicted AoA variation with azimuth position is shown in Figure 8. At the $-90^{\circ}$ and $+90^{\circ}$ positions the blade chord is parallel with the local flow direction. Between $-90^{\circ}$ and $+90^{\circ}$ positions the blade passes through the upwind cycle of rotation and through the downwind cycle between $+90^{\circ}$ and $+270^{\circ}$ positions. A reduction in the maximum AoA is observed over the downwind cycle due to the induced velocity field. The normal force coefficient of the element shown in Figure 8 tracks the AoA for $|\mathrm{AoA}|<17^{\circ}$. Above this value, the blade element stalls and normal force is reduced. Owing to dynamic flow considerations, flow separation and reattachment does not necessarily occur at the same AoA. The tangential force coefficient variation, also shown in Figure 8, is reduced over the stalled regions owing to the increased drag but remains positive except where the element is in deep stall.

The NOVA concept aims to minimise the peak OTM resulting from these cyclic blade forces to reduce stresses on the drivetrain and support structure. It achieves this using inwardly inclined blades to reduce the OTM arm; these are supported by Vshaped rotor arms. To illustrate this, Figure 9 shows the profiles 


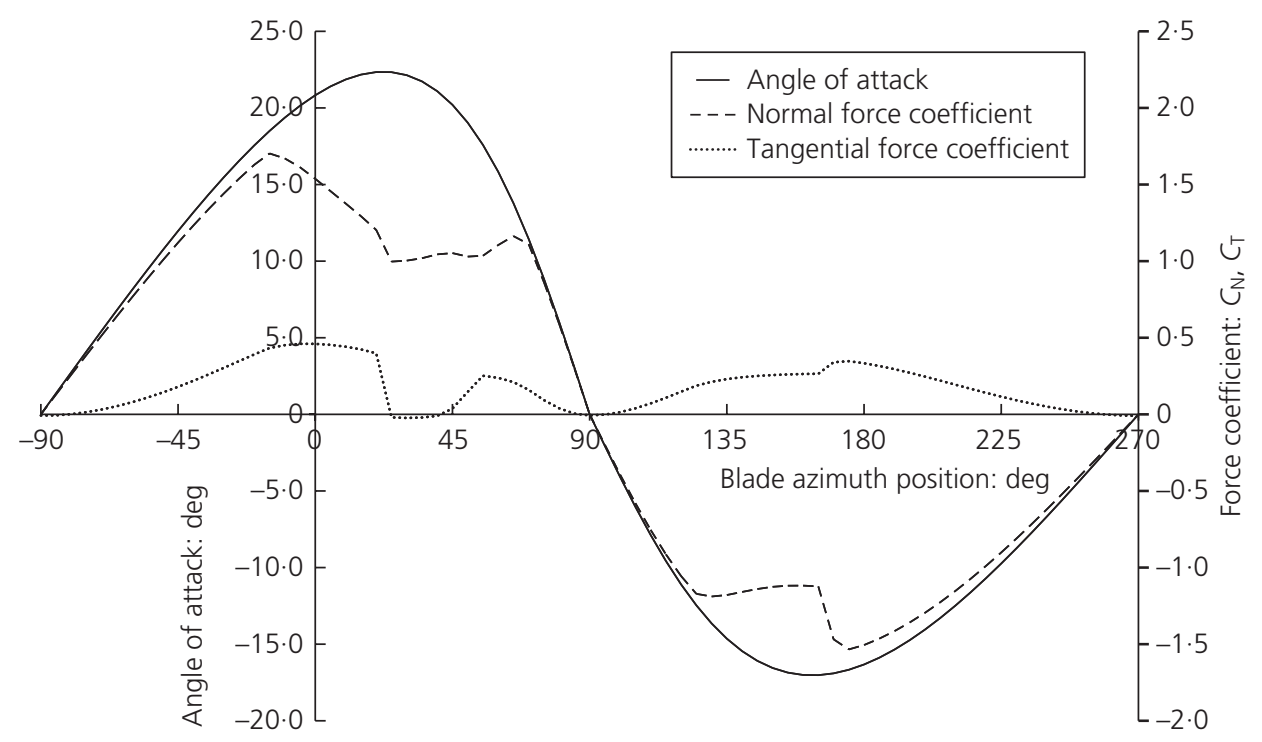

Figure 8. Variation of angle of attack and loads with blade azimuth position

of a V-rotor with two supporting arms and a single blade midmounted at the spanwise extent of each arm. For this example, the arms are inclined at $59^{\circ}$ to the vertical. These profiles compare a configuration with vertical sails and those with inwardly inclined sails (positive cant angles) and outwardly inclined sails (negative cant angles).

The influence of sail cant angle (for the rotor illustrated in Figure 9) on the mean rotor torque and OTM is shown in Figure 10 for a single operating condition of $4 \mathrm{r} / \mathrm{min}$ at a wind speed of $10 \mathrm{~m} / \mathrm{s}$. For this comparison, the effect of wind shear is neglected and torque/OTM data are normalised against that for the vertical position. Figure 10 shows that the maximum torque is generated with a vertical sail position and reduces if the sail is inclined either inwardly or outwardly. However, if the sail is inclined inwardly the OTM is reduced significantly with an optimum cant angle of approximately $40^{\circ}$. Clearly, if the arm cant angle is increased (relative to the vertical) then the sail cant angle can be reduced to deliver a minimum OTM and potentially higher torque. However, this profile would

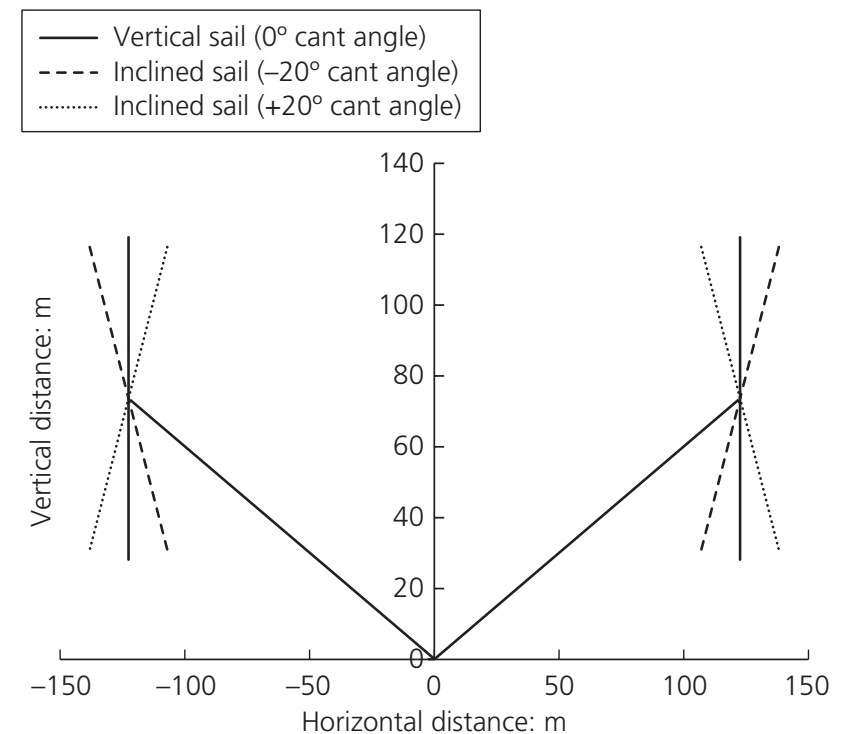

Figure 9. Profiles to illustrate different sail cant angles of a V-VAWT 


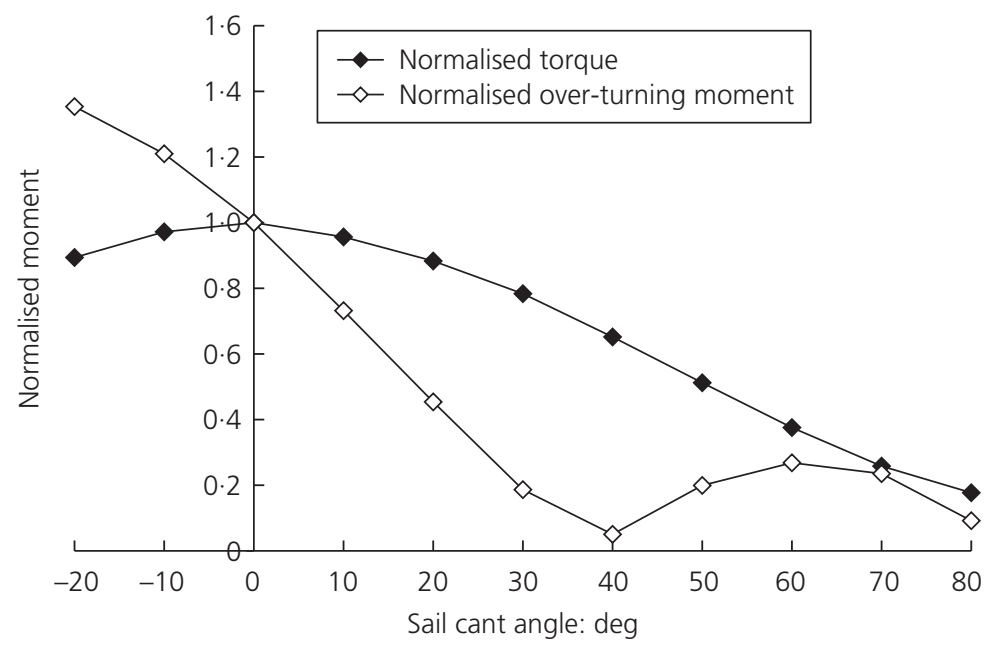

Figure 10. Effect of sail cant angle on torque/OTM

also reduce the elevation of the sail and therefore the loads due to the increased wind shear.

Therefore, for a given rotor torque there is no unique rotor profile that minimises the OTM and the optimum configuration shape is a compromise between aerodynamic efficiency and mechanical and structural constraints for the bearing and support structure.

\subsection{Design results}

With a primary design objective to reduce the cost of electricity, largely through lower cost manufacturing, the total rotor internal volume was selected as an appropriate objective function to represent manufacturing and assembly costs. Mechanical and structural constraints included in the design process were

- electrical power of $10 \mathrm{MW}$, assuming an $88 \%$ drivetrain efficiency

- a peak OTM limit for the rotor of $140 \mathrm{MNm}$

- a minimum clearance of rotor components of $11 \mathrm{~m}$ above sea level

- a maximum unsupported blade span of $40 \mathrm{~m}$

- a maximum strut span limited to $25 \mathrm{~m}$ due to buckling considerations

- no overlapping blades

- sail chord greater than local arm chord.

Structural engineers provided span limits for sails and struts and the peak OTM limit was based on advice from a leading UK bearing manufacturer. For multiple sail designs, the optimiser ensured that no sail overlap occurred to avoid the losses that would be generated from multiple wake interactions. Initially, this was imposed as a geometric constraint but it was later established that the aerodynamic penalty was sufficient in preventing overlap. For most designs it was necessary to perform a dual-point design with rotor power constrained at the primary design point (i.e. $13 \mathrm{~m} / \mathrm{s}$ wind speed, $4 \mathrm{r} / \mathrm{min}$ ) and OTM constrained at both design points, where the secondary design point represents the cut-off condition (i.e. $35 \mathrm{~m} / \mathrm{s}$ wind speed, $4 \mathrm{r} / \mathrm{min}$ ) at which aerodynamic loads are generally highest. In general, about 25 variables would be controlled by the optimiser within upper and lower bounds, although not all variables were always active.

A typical design history is illustrated in Figure 11 for a singlepoint design of a V-rotor with two sails and 16 design variables. Fifty design cycles were completed requiring 867 different geometry evaluations over a $2 \mathrm{~h}$ elapsed period on a standard desktop computer. The half-rotor profiles are shown in Figure 12 corresponding to the initial and final design cycles. Constraint functions are satisfied if the function, $f \leq 0$, so initially only constraint 3 , requiring the sail chord to be greater than the local arm chord, is not satisfied. The rotor power is initially $9 \%$ greater than the target value. For the first five design cycles sail chord is increased to satisfy constraint 3, resulting in an increase of rotor power, OTM and internal volume. After design cycle 5 the span of the arm and two sails is gradually reduced resulting in a reduced rotor power, OTM and internal volume. In this design run, the span, chord and cant angle of the two sails are set to the same values. At design cycle 42 the rotor power equals the target value within the required tolerance and further reductions in span are only achieved following a $2^{\circ}$ increase in arm cant angle and a $0.2^{\circ}$ increase in the sail cant angle. With the increase in cant angle, the lower sail can move further outboard on the arm without overlapping the outer sail, to increase elevation and angular velocity. These final changes allow the target rotor power to be maintained while reducing the OTM and internal volume further. The final design of this run achieves a $3 \%$ reduction 


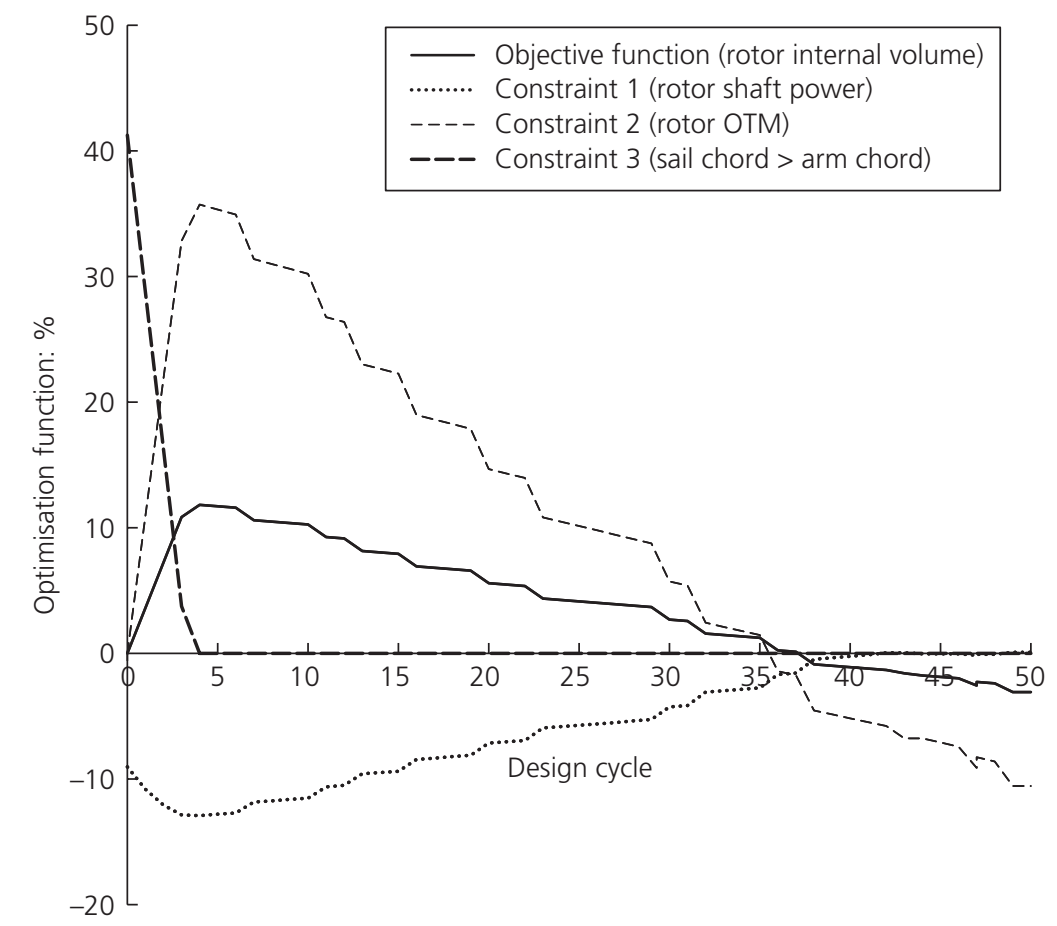

Figure 11. Example design history

in rotor internal volume and $11 \%$ reduction in OTM with all constraints satisfied.

As the design procedure could not optimise integer variables, initial sensitivity studies investigated the number of rotor arms and also the number of sails per arm. It was found that increasing the number of arms to three, for example, increases the sail-wake losses giving a lower mean wind speed through the rotor and no significant improvement in aerodynamic

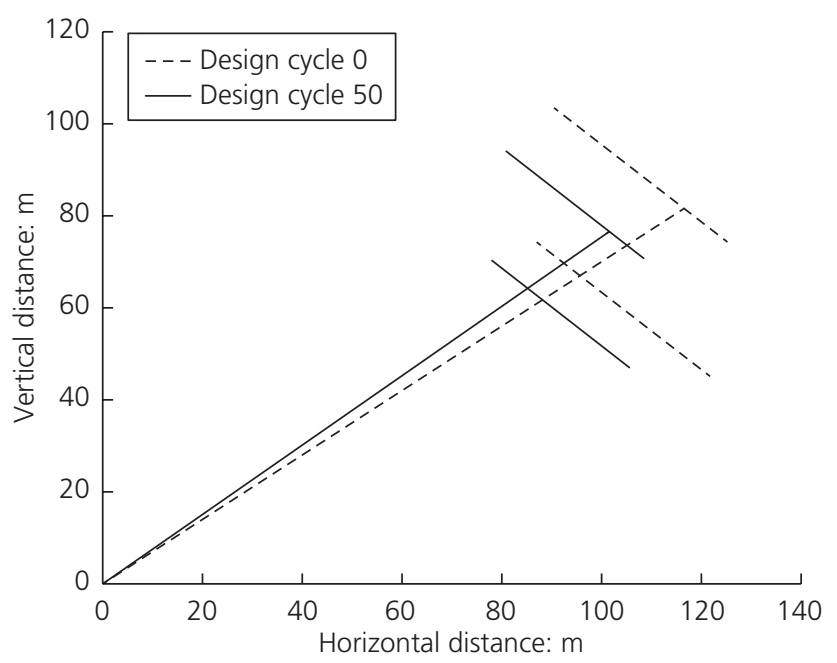

Figure 12. Half rotor profiles efficiency or reduction in rotor size. Therefore, an initial design decision was to constrain the design to a two-arm (Vrotor) configuration, particularly as self-starting characteristics were not required.

The original NOVA concept pictured in Figure 4 featured four sails per arm, positioned such that no sails overlap at any given height in order to minimise losses due to sail-wake interactions. However, this requirement results in low-aspect-ratio sails that are less efficient owing to higher induced drag and tip losses and higher interference drag due to the number of junction regions. Furthermore, analysis of this profile showed that the lower sails contribute significantly less torque owing to their lower elevation and angular velocity. Consequently, all design optimisation studies focused on one and two-sail designs.

The previous design example of a two-sail rotor fixed the span, chord and cant angles to be the same. However, if these are allowed to vary independently, a very different configuration develops. Figure 13 compares the results of two dual-point designs for a one-sail configuration illustrated on the left-hand side and a two-sail design on the right-hand side. With one sail a support strut is necessary to ensure the unsupported blade span is less than $40 \mathrm{~m}$. For the two-sail design, the requirement to avoid overlapping sails tended to increase the span of the upper sail to the maximum allowable limit while reducing the span of the lower sail and moving it closer to the hub. This was not unexpected because the increased aspect ratio of 


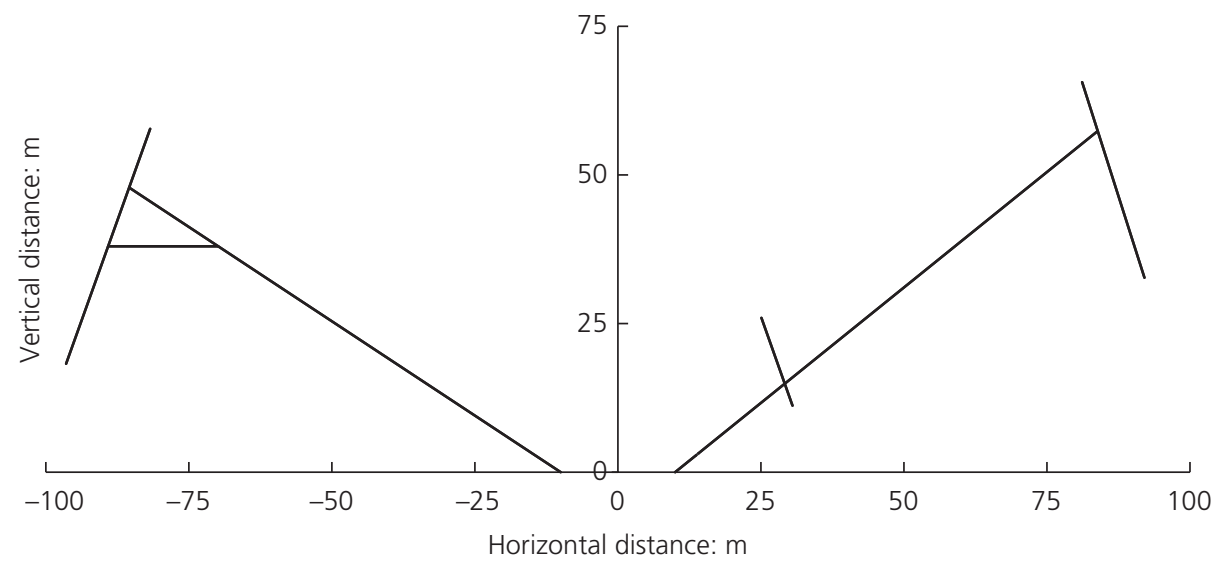

Figure 13. Alternative profiles of a $5 \mathrm{MW}$ V-VAWT

the outer sail improves aerodynamic efficiency. Clearly, the maximum allowable span was a key design parameter, driven by structural and manufacturing considerations. The overlap constraint also resulted in a higher arm cant angle for the two-sail design in order to increase sail elevation. In general, if the OTM limit is relaxed then the arm and sail cant angles increase to give greater elevation of the sails and increased torque. These design studies showed that, provided the unsupported sail span is less than $40 \mathrm{~m}$, a single sail design with supporting strut(s) gives the optimum configuration that is, with the lowest internal volume and therefore bill of materials.

Dual-point designs were found to produce a powercurve with a peak at the primary design point as shown in Figure 14. A more preferable powercurve would feature a flat top corresponding to the rated power of the turbine and a gradual reduction in power at higher wind speeds due to stall regulation. The detailed design of section profiles was not considered in this study, although varying the local twist and thickness allows the section tangential thrust to be maximised and the stall characteristics to be tailored to provide passive stall control at high wind speeds. Therefore, after the configuration profile shape was optimised for the rated power, it was beneficial to refine this design and improve performance over a greater range of wind speeds.

Multi-point designs were performed with five to six design points (i.e. wind speeds). An objective function was formulated as an integration of the differences between the target and actual powercurve shapes, with weighting factors around the primary design point. Blade section twist angle and thickness were the only shape parameters to be optimised. These could only vary linearly along the span to avoid double curvature of the surfaces and reduce manufacturing costs. Shaping the powercurve in this way removed the peak around $13 \mathrm{~m} / \mathrm{s}$ and increased efficiency over a greater range of wind speeds, as illustrated by the multi-point design result shown in Figure 14.
The final 10 MW Aerogenerator design was scaled by approximately $70 \%$ to a $5 \mathrm{MW}$ design for comparison with an existing REpower 5 MW HAWT turbine shown in Figure 15 (dashed lines represent support struts). The Aerogenerator design operates at a significantly lower elevation than the HAWT, but with wind shear less pronounced offshore the V-VAWT turbine still achieves reasonable aerodynamic efficiency with a power coefficient of 0.38 and with a significantly lower OTM and centre of gravity than the HAWT. Furthermore, it is anticipated that turbine spacing within an offshore wind farm would be similar to an equivalent HAWT wind farm, with no penalty for the larger diameter. An artist's impression of the final $10 \mathrm{MW}$ design, dubbed the 'Sycamore turbine', is shown in Figure 16 on a floating semi-sub platform.

\section{Conclusions}

The NOVA conceptual design study, commissioned by the Energy Technologies Institute, performed a technological, economic and environmental assessment of a novel V-VAWT configuration and showed that the low-stress design combined with high availability would be more cost effective compared with a baseline conventional offshore HAWT wind farm. The

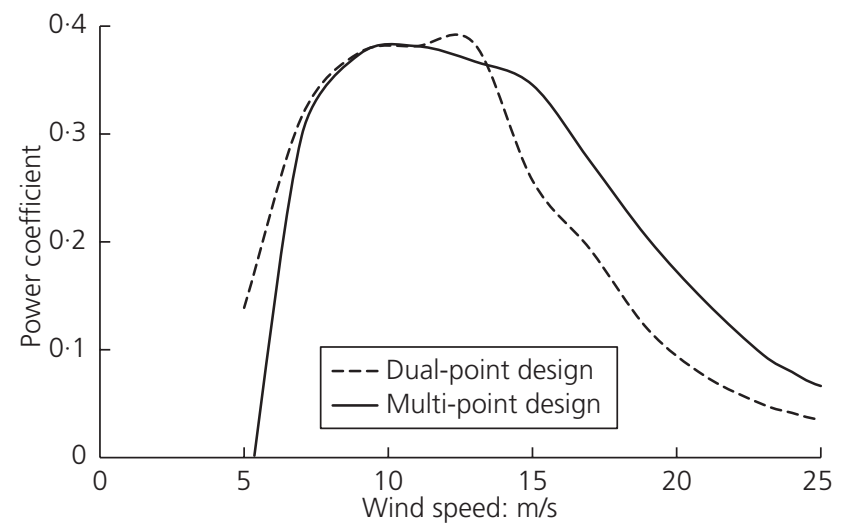

Figure 14. Powercurve optimisation example 


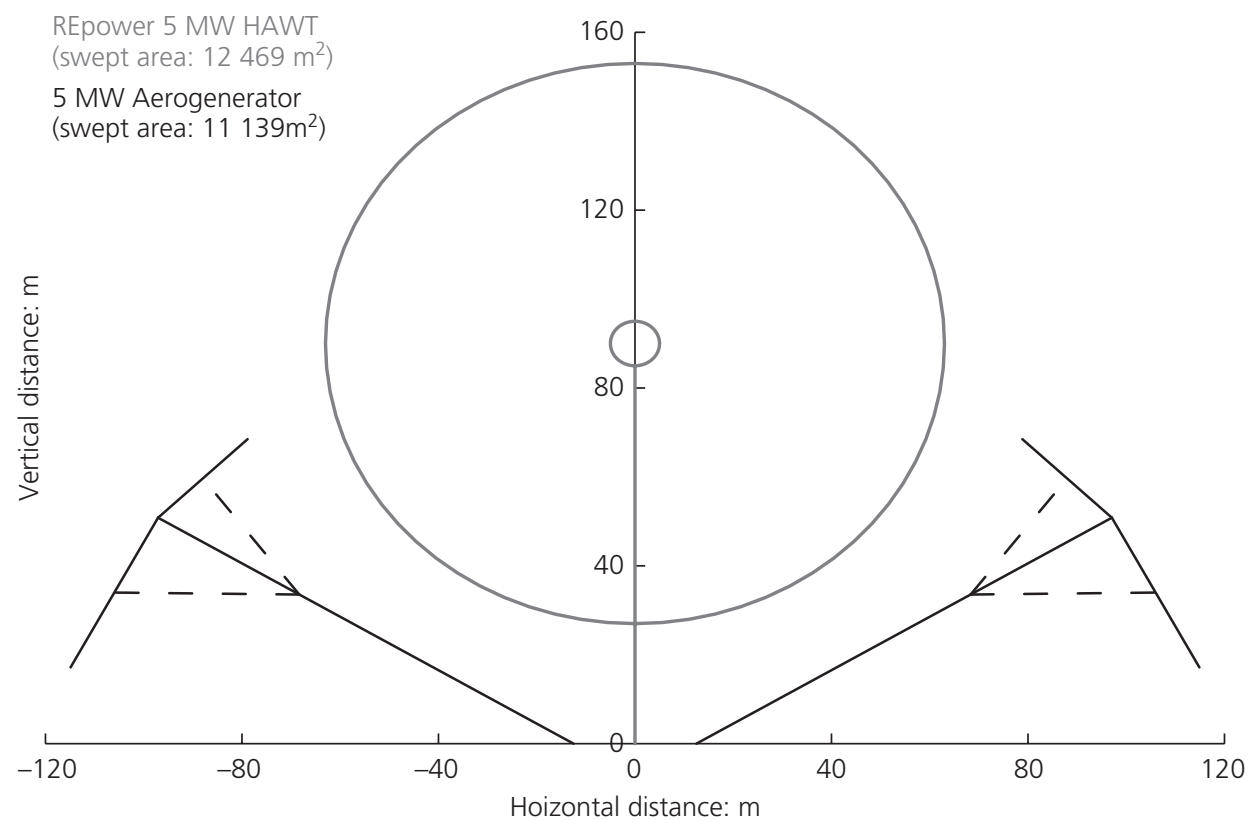

Figure 15. Comparison of 5 MW HAWT and Aerogenerator profiles

Aerogenerator concept combines a V-rotor with several blades or sails positioned along the span that are inclined to minimise aerodynamic OTMs. This paper describes the shape optimisation of a $10 \mathrm{MW}$ Aerogenerator V-VAWT rotor. The need to maximise torque and to minimise OTMs leads to conflicting design requirements so a numerical optimisation procedure was developed to obtain a compromise between aerodynamic efficiency and mechanical and structural constraints for the bearing and support structure. The design studies propose a 'sycamore'shaped rotor as a credible alternative to current offshore wind turbine designs and concepts.

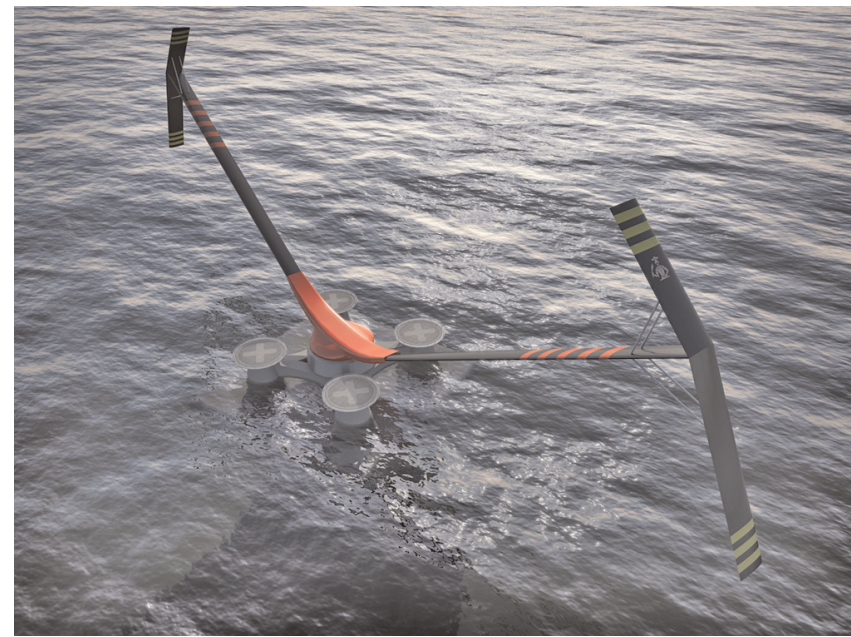

Figure 16. 10 MW Aerogenerator concept (courtesy of Wind Power Ltd and Grimshaw, 2010)

\section{Acknowledgements}

The author would like to acknowledge the support of Wind Power Ltd, the Energy Technologies Institute and the NOVA Consortium partners.

\section{REFERENCES}

Akimoto H, Tanaka K and Uzawa K (2011) Floating axis wind turbines for offshore power generation - a conceptual study. Environmental Research Letters 6: doi:10.1088/1748-9326/6/ 4/044017.

Alderman JE and Shires A (2006) Aerodynamic Optimisation of the A350 Configuration Using Flite3D-CODAS. Airbus UK, customer report QinetiQ/06/00512.

Berg DE (1983) An improved double-multiple streamtube model for the Darrieus-type vertical axis wind turbine. Proceedings of the 6th Biennal Wind Energy Conference and Workshop. ASES, Minneapolis, MN, USA, pp. 231-233.

BWEA (British Wind Energy Association) (2009) UK Offshore Wind: Charting the Right Course-Scenarios for Offshore Capital Costs for the Next Five Years. See http:// www.gl-garradhassan.com/assets/downloads/UK_Offshore_ Wind_Charting_the_Right_Course.pdf (accessed 19/11/2012).

Clare R and Mays ID (1989) Development of vertical axis wind turbine. ICE Proceedings, Part 1 86(5): 857-878, http://dx.doi.org/10.1680/iicep.1989.3160.

Collu M, Kolios A, Chahardehi A and Brennan FP (2010) A comparison between the preliminary design studies of a fixed and a floating support structure for a $5 \mathrm{MW}$ offshore wind turbine in the North Sea. In Marine \& Offshore Renewable Energy - Developments in Wind, Wave, Tidal and Current Technology. RINA HQ, London, UK. 
Dodd J (2011) Work starts on prototype floating vertical-axis turbine. Wind Power Monthly. See www.windpowermonthly. com/news/1050768 (accessed 25/05/2012).

Doherty JJ and Lovell DA (1994) Aerodynamic Design of Aerofoils and Wings Using a Constrained Optimisation Method. ICAS, Anaheim, CA, USA, ICAS-94-2.1.2.

Eriksson S, Bernhoff H and Leijon M (2008) Evaluation of different turbine concepts for wind power. Elsevier Renewable and Sustainable Energy Reviews 12(60): 1419-1434.

Gormont RE (1973) A Mathematical Model of Unsteady Aerodynamics and Radial Flow for Application to Helicopter Rotors. Boeing Vertol Company, Philadelphia, PA, USA, US Army Air Mobility Research and Development Laboratory Technical Report 72-67.

Kaminski I (2011) ETI Shows Viability of Vertical Axis Offshore Wind Turbines. Renewable Energy Focus. See http://www.renewableenergyfocus.com/view/16425 (accessed 25/05/2012).

Kirke BK and Lazauskas L (2008) Variable pitch Darrieus water turbines. Journal of Fluid Science and Technology 3(3): 430-438.

Ljungstrom O (1986) Innovative concepts in axial and crossflow wind turbine systems. Proceedings of European Wind Energy Association Conference, Rome, Italy.

Low Carbon Innovation Coordination Group (2012) TINA Report: Technology Innovation Needs Assessment: Offshore Wind Summary Report. Low Carbon Innovation Coordination Group, DECC, UK. See http://www.decc. gov.uk/assets/decc/11/funding-support/fund-opportunities/ 4467-tina-offshore-wind-summary.pdf (accessed 19/11/2012.

Marsh G (2005) Wind turbines: how big can they get? Refocus 6(2): 22-24; 27-28.

Marsh G and Peace S (2005) Tilting at windmills: utility-scale VAWTs: towards $10 \mathrm{MW}$ and beyond? Refocus 6(5): 37-42. See http://dx.doi.org/10.1016/S1471-0846(05)70457-1 (accessed 25/10/2012).

Masse B (1981) Description de Deux Programmes d'Ordinateur pour le Calcul des Performances et des Charges Aerodynamiques pour les Eoliennes a Axe Verticall. IREQ2379, Hydro-Quebec Research Institute, Varennes, Quebec, Canada (in French).

Mays ID, Morgan CA, Anderson MB and Powles SJR (1990) Experience with the VAWT 850 demonstration project. In Proceedings of the European Wind Energy Association Conference, Madrid, Spain.

Morgan CA, Mays ID, Anderson MB and Gardner P (1989) The demonstration of a stall regulated $100 \mathrm{~kW}$ vertical axis wind turbine. Proceedings of the European Wind Energy Association Conference, London, UK.

NOVA Consortium (2010) NOVA Phase I Feasibility Study Final Report. Report produced for the Energy Technologies Institute, Loughborough, UK.
Paraschivoiu I (1988) Double-multiple streamtube model for studying vertical-axis wind turbines. Journal of Propulsion and Power 4(4): 370-378.

Price TJ (2006) UK large-scale wind power programme from 970 to 1990: the Carmarthen bay experiments and the Musgrove vertical-axis turbines. Wind Engineering 30(3): 225-242.

Roach PE and Turner JT (1985) Secondary loss generation by gas turbine support struts. International Journal of Heat Fluid Flow 6(2): 79-88.

Sharpe DJ, Taylor DA and Boyle GA (1987) Developments with the 'V'-type vertical axis wind turbine. Proceedings of the 9th British Wind Energy Association Conference, Edinburgh, UK.

Sheldahl RE (1981) Aerodynamic characteristics of seven symmetrical airfoil sections through 180-degree angle-ofattack for use in aerodynamic analysis of vertical axis wind turbines. Sandia National Laboratories, Albuquerque, NM, USA, report SAND80-2114.

Shires A and Alderman JE (2004) Racing car rear wing aerodynamic design optimisation. Proceedings of 5 th MIRA International Vehicle Aerodynamics Conference, Warwick, UK.

Snieckus D (2012) Deep-water vertical-axis wind turbine gets last dry run. Recharge. See http://www.rechargenews.com/ business_area/innovation/article296513.ece (accessed 20/09/ 2012).

Sutherland HJ, Berg DE and Ashwill TD (2012) A retrospective of VAWT Technology. Sandia National Laboratories, Albuquerque, NM, USA, report SAND2012-0304.

Tangler JL (2000) The Evolution of Rotor and Blade Design. NREL Conference Paper NREL/CP-500-28410, July 2000. See http://www.nrel.gov/docs/fy00osti/28410.pdf. (accessed 20/09/2012).

Tavner PJ, Xiang J and Spinato F (2007) Reliability analysis for wind turbines. Wind Energy 10(1): 1-18.

Vita L, Paulsen US, Pedersen TF, Madsen HA and Rasmussen F (2009) A novel floating offshore wind turbine concept. Proceedings of European Wind Energy Association Conference, Marseille, France.

\section{WHAT DO YOU THINK?}

To discuss this paper, please email up to 500 words to the editor at journals@ice.org.uk. Your contribution will be forwarded to the author(s) for a reply and, if considered appropriate by the editorial panel, will be published as a discussion in a future issue of the journal.

Proceedings journals rely entirely on contributions sent in by civil engineering professionals, academics and students. Papers should be 2000-5000 words long (briefing papers should be 1000-2000 words long), with adequate illustrations and references. You can submit your paper online via www.icevirtuallibrary.com/content/journals, where you will also find detailed author guidelines. 